\title{
Madrigais em castelhano na obra de Manuel Botelho de Oliveira
}

Anne Navarro Miranda I UNI-BH

Resumo: Este artigo analisa dois madrigais escritos em lingua espanhola pelo poeta brasileiro Manuel Botelho de Oliveira.

Palavras-chave: Literatura Brasileira, Poesia Brasileira, Poesia Barroca.

\section{I}

$\mathrm{Na}$ "Dedicatória" de sua obra Música do Parnasso, Manuel Botelho de Oliveira revelou estar ciente de que era o primeiro poeta brasileiro a publicar um livro de poesia. A esse respeito deixou registradas, em fórmula de afetada modéstia, as seguintes palavras:

Ao meu [engenho], pôsto que inferior aos de que é tão fértil êste país, ditaram as Musas as presentes rimas, que me resolvi expor à publicidade de todos, para ao menos ser o primeiro filho do Brasil que faça pública a suavidade dos metros, já que não o sou em merecer outros maiores créditos na Poesia.

1. OLIVEIRA, 1953, tomo I, p. 3. 
Com a publicação da obra, que recebeu do seu autor o título de Música do Parnasso dividida em quatro coros de rimas portuguesas, castelhanas, italianas e latinas, com seu descante cômico redusido em duas comedias, em 1705, inaugura-se, na poesia brasileira, uma importante tradição: a das publicações de obras líricas. A obra de que tratamos possui, portanto, uma importância histórica inegável.

O livro se compõe, conforme anuncia o título, de poemas escritos em quatro línguas: a portuguesa, a castelhana, a italiana e a latina. A cada uma dessas línguas o poeta dedicou uma parte específica da obra, a que chamou, muito apropriadamente, "coro". São, pois, quatro os coros da Música do Parnasso: Primeiro Coro de Rimas Portuguesas, Segundo Coro das Rimas Castelhanas, Terceiro Coro das Rimas Italianas e Quarto Coro das Rimas Latinas. No Coro das Rimas Castelhanas encontram-se sonetos, canções, madrigais, décimas, e romances - nessa ordem.

Quis o poeta escrever em quatro línguas para demonstrar que "pode uma só Musa cantar com diversas vozes" e para que a sua obra fosse reconhecida, "se não pela elegância dos conceitos, ao menos pela multiplicidade das línguas." E o fez, como já ficou dito, em sua língua materna e em três línguas estrangeiras. O Coro de Rimas Portuguesas e o Coro das Rimas Castelhanas são mais extensos e de organização mais complexa que os outros dois: ambos apresentam uma divisão interna - em Versos Amorosos e Versos Vários - que não ocorre no Coro das Rimas Italianas nem no Coro das Rimas Latinas, que são mais breves. Sobre a menor extensão desses dois últimos coros, o poeta, no "Prólogo ao Leitor", afirma que "estão abreviados, porque além desta composição não ser vulgar para todos, bastava que se desse a conhecer em poucos versos."

O fato de Manuel Botelho de Oliveira haver composto versos em línguas estrangeiras, o seu polilingüismo - que na época da realização da obra, segundo podemos entender da defesa que o poeta fez de seus escritos, seria um motivo de valorização deles - tem servido a um ponto de vista contrário, ou seja, para sustentar a reserva com que o olhar da crítica tem sido dirigido à

2. OLIVEIRA, 1953, tomo I, p. 9.

3. OLIVEIRA, 1953, tomo I, p. 10. 
sua obra. Botelho de Oliveira, por esse motivo - o outro seria a ausência de "cor local" em sua obra -, tem sido considerado, de modo simplista e anacrônico, apenas um emulador da poesia estrangeira, além de pouco "brasileiro".

Apesar dessa tradição, nas últimas décadas do século passado as diversas facetas da obra do poeta passaram a despertar um crescente interesse nos estudiosos. Carmelina Magnavita Rodrigues de Almeida dedicou-se, numa tese de concurso público, ao estudo dos poemas escritos em italiano da Música do Parnasso; João Roberto Inácio Ribeiro tratou da parte em latim; Ivan Teixeira e Marlene Machado Zica Vianna abordaram a parte da obra poética escrita em português; e Enrique Rodrigues-Moura estudou parte dos poemas escritos em espanhol. O interesse desses estudiosos pela Música do Parnasso parece sinalizar que a obra de Manuel Botelho de Oliveira é merecedora de outros maiores créditos, sendo digna de reavaliação.

Um dos propósitos deste artigo é, a partir do estudo de dois madrigais em língua espanhola, contribuir para o conhecimento da parte da obra de Manuel Botelho de Oliveira escrita naquela língua e para a reavaliação do poeta e do conjunto de seus escritos. Os dois madrigais que constituem o objeto deste estudo se aproximam por conterem uma espécie de teoria do olhar. No primeiro deles, intitulado "Anarda vista, e amada", os olhos são janelas para entrar; no segundo, cujo título é "Amor declarado pelos olhos", está dito que os olhos são, também, janelas para sair. Para amar Anarda basta vê-la. E o amor, que a visão dela desperta, é inevitavelmente demonstrado pelos olhos do amante.

O madrigal, na Música do Parnasso, comparece em três das quatro partes líricas em que o livro está organizado: essa forma poética só não ocorre no Coro das Rimas Latinas. No primeiro coro, escrito em língua portuguesa, o madrigal faz parte somente dos Versos Amorosos, não compondo os Versos Vários; o mesmo ocorre com o segundo coro, escrito em espanhol. Isso está de acordo com o fato de o tema próprio do madrigal ter sido, ao longo de grande parte da história dessa forma poética, o amor.

Na Música do Parnasso há, no total, quarenta e oito madrigais: vinte e três no Coro de Rimas Portuguesas, dezoito no Coro das Rimas Castelhanas e sete no Coro das Rimas Italianas. Para compor todos os madrigais da obra, Manuel Botelho de Oliveira adotou o madrigal espanhol como modelo, e nos estreitos limites da forma adotada teve de conter a manifestação de sua expressão pessoal. Os madrigais de Botelho de Oliveira apresentam uma estrofe 
única composta por versos cujo número varia entre quatro ${ }^{4}$ e doze, ${ }^{5}$ predominando os de seis a oito versos, e terminam sempre por dois versos de rimas emparelhadas.

Se Manuel Botelho de Oliveira, adepto do rigor no uso das formas poéticas e da adequação delas ao tema de que tratam, opera no modelo adotado de madrigal alguma inovação, o faz nas rimas. O traço distintivo do madrigal espanhol, no que respeita à rima, é o fato de que o remate se efetua com rimas emparelhadas - nenhuma prescrição há para as rimas dos versos que antecedem os dois versos finais. Chegou-se a verificar, nos madrigais escritos por poetas espanhóis da época, o caso de existirem versos soltos, ou seja, versos cujas últimas sílabas não correspondem, do ponto de vista sonoro, às sílabas finais de qualquer outro verso do poema.

Em Música do Parnasso, os dois últimos versos de cada madrigal apresentam rimas emparelhadas. O uso desse tipo de rima, nos madrigais de Botelho de Oliveira, se estende à maioria dos outros versos: no coro escrito em castelhano, por exemplo, das dezoito composições, doze possuem entre seis e oito versos e seguem o esquema de rimas aabbcc(dd).

Dos seis madrigais restantes, os únicos dois de cinco versos apresentam rimas alternadas nos quatro versos iniciais, constituindo o quarto e o quinto um par de versos de rimas emparelhadas, segundo o esquema ababb; outros dois, de oito versos, possuem os quatro primeiros com rimas alternadas e os demais com rimas emparelhadas, segundo o esquema ababccdd; um dos madrigais, também de oito versos, tem rimas abraçadas nos primeiros quatro e rimas emparelhadas nos restantes, segundo o esquema abbaccdd; e há um único caso, nas rimas castelhanas, em que aparecem versos soltos: isso se dá no décimo terceiro madrigal, intitulado "Ais repetidos", em que os seis versos obedecem ao esquema abccdd.

Como se vê, o poeta explorou várias possibilidades aplicáveis ao madrigal, cuidando de manter, em suas composições, as características necessárias ao bom desempenho da forma. Do exame dos esquemas de rima

4. O único madrigal com quatro versos pertence ao Coro das Rimas Italianas, e traz o título de "Sol com Anarda". Seus versos são heptassílabos e suas rimas se organizam conforme o esquema aabb.

5. Em todo o conjunto de madrigais da obra, somente um, intitulado "Doutoramento amoroso", possui dez versos. Também há um único madrigal de doze versos: "Encarecimento dos rigores de Anarda". Ambos pertencem ao Coro de Rimas Portuguesas. O esquema de rimas do primeiro é abaBccddEE; o do segundo, aAbBcCdDeeFF. 
aplicados no conjunto dos madrigais escritos em espanhol - e que se repetem nos madrigais escritos nas outras duas línguas românicas - decorre a constatação de que a obra Música do Parnasso foi resultado da obediência às normas e da adesão ao código literário vigente na época.

Quanto ao metro, embora haja no conjunto da obra dois madrigais compostos exclusivamente de versos heptassílabos, ${ }^{6}$ todos os demais combinam versos de onze e de sete sílabas, em livre alternância.

Tal como ocorre em muitas das composições presentes na obra, o rigor da amada é o objeto de dez dos dezoito madrigais escritos em espanhol: "Anarda negando certo favor", "Amante secreto", "Música, e cruel”, "Rigor e fermosura", "Amor Medroso", "Ao mesmo [assunto: Anarda vendo-se a um espelho]", "Etna amoroso", "Ais repetidos", "Doença amorosa", "Guerra amorosa" e "Retrato amoroso".

O madrigal espanhol, herdeiro do italiano, não tem uma definição muito exata: a sua forma métrica, muito variável, resulta da livre combinação de versos hendecassílabos e heptassílabos. Também a extensão é instável, embora se organize em uma única estrofe, com número de versos que variam entre oito e doze. No entanto, há registros de madrigais de quatro versos e outros de mais de trinta. As notas características distintivas do madrigal são o uso de rimas invariavelmente consoantes cuja disposição é livre, podendo haver versos soltos; e o fato de terminarem sempre com um par de versos de rimas emparelhadas. Predomina o assunto amoroso, que, devido à brevidade da forma, é de expressão pouco complexa. No século XVII o madrigal espanhol conheceu a sua maior difusão, tendo sido Francisco de Quevedo - e não Gôngora, a quem Manuel Botelho de Oliveira tem sido acusado de imitar - o poeta mais fecundo na produção de madrigais do Século de Ouro. ${ }^{7}$

6. É o que se observa nos madrigais "Doença Amorosa" e "Sol com Anarda". O primeiro deles tem seis versos e pertence ao Coro das Rimas Castelhanas, e o segundo possui quatro versos e está incluído no Coro das Rimas Italianas.

7. Cf. BAEHR, 1989, p. 407. 


\section{II}

\section{ANARDA VISTA, E AMADA}

madrigal III

Cuando las luces de tus ojos veo,

Se enciende mi deseo,

El corazón se inflama

De suerte pues, que en la amorosa llama,

Las que en tus ojos son luces vivientes,

Son en mi corazón llamas ardientes.

O terceiro madrigal das rimas castelhanas, tal como ocorre, pela adoção do modelo espanhol, em todos os demais da lavra de Manuel Botelho de Oliveira, compõe-se de uma única estrofe em que estão combinados livremente versos hendecassílabos e heptassílabos. Trata-se de um poema breve, composto de seis versos com rimas consonantes. Não só termina com um par de versos de rimas emparelhadas: esse artifício se estende a todas as rimas anteriores. Os versos de metro longo, em número de quatro, predominam sobre os de metro curto, que são dois. O esquema de rimas deste madrigal é AabBCC.

Do ponto de vista da sintaxe, o poema está construído, de maneira simétrica, em dois blocos de sentido, com cada conjunto de três versos correspondendo a uma unidade. O primeiro bloco contém a seguinte idéia: "Quando vejo as luzes dos teus olhos, o meu desejo se incendeia e o meu coração se inflama”. Embora não esteja presente o possessivo de primeira pessoa no terceiro verso do poema, "El corazón se inflama", por analogia ao que vai dito naquele que o antecede, "Se enciende mi deseo", em que a marca de primeira pessoa é inequívoca, pode-se atribuir o coração inflamado ao amante, possuidor também do desejo que se revela no segundo verso.

Essa primeira parte do poema esboça uma narrativa, naturalmente feita em primeira pessoa. O poeta relata que a luminosidade dos olhos da amada acende o seu desejo de amante, e, penetrando ainda mais fundo, chega-

8. Adotaremos, para expor os esquemas de rimas dos madrigais analisados, letras maiúsculas para representar versos longos e letras minúsculas para os curtos. 
lhe ao coração, onde se acende a chama amorosa. A luz dos olhos de Anarda tem dois efeitos, repercutindo duplamente no poeta - ao acender-lhe o desejo e ao inflamar-lhe o coração. A repercussão do olhar da amada faz-se, portanto, em dois planos: um, sensorial, corresponde ao desejo - é o plano da sensualidade; o outro, mais espiritualizado, afeta-lhe o coração - é o plano do sentimento.

A escolha dos verbos que se referem às palavras "deseo" e "corazón" não se dá por acaso. Eles pertencem ao campo semântico do fogo, assim como as palavras, "llama", "luces" e "llamas", na segunda metade do poema.

Os três versos do segundo bloco sintático já não são sequer alusivamente narrativos: o poeta expõe o resultado da ação de ver os olhos da amada, ou seja, ele faz o retrato de seu estado interior. No plano nocional, a segunda metade do poema, introduzida pela expressão "De suerte que...", desenvolve as conseqüências sofridas pelo poeta, no plano do sentimento e da interioridade, em decorrência do fenômeno sensorial da visão. Em outras palavras: a segunda metade do poema é desdobramento do último verso da primeira metade, ao qual se encontra vinculada pela rima: "inflama / llama".

$O$ poeta busca, de maneira engenhosa, traduzir em palavras o resultado interior da experiência exterior propiciada pela visão e, simultaneamente, a diferença do mesmo fenômeno luminoso nele e em Anarda: "De modo que, na amorosa chama (ou seja, no estado amoroso), as luzes que nos teus olhos são seres viventes, no meu coração são chamas ardentes".

A omissão do possessivo identificador da primeira pessoa, constatada no último verso do bloco anterior, também nesse segundo bloco se verifica: a chama amorosa inflama o coração do poeta, do "eu" que fala no poema. Essa elipse unifica os versos centrais do poema - o terceiro, que fecha o primeiro bloco de sentido, e o quarto, que abre o segundo bloco - e não prejudica a sua plena compreensão, já que, sabe-se, o coração inflamado e a chama amorosa são atributos daquele que ama. É digno de nota que a referida omissão ocorra sempre em contexto determinado: quando o poeta fala do sentimento que a visão de Anarda prontamente lhe desperta no coração. As menções feitas ao coração, órgão do corpo humano associado desde sempre ao sentimento amoroso, ocupam os versos centrais do poema - lugar que ocupa no corpo o coração.

Ainda nesse segundo segmento do poema concorrem duas "luminosidades": a primeira é a que emana dos olhos da amada; a segunda, sua conseqüência, é a chama do amor, localizada no coração do amante. As luzes dos olhos de Anarda, tal como ficou dito no primeiro conjunto de três versos, 
entram em correspondência com as chamas do coração do poeta, já que estas são produzidas por aquelas.

Se a organização sintática do madrigal se faz em dois conjuntos de versos, do ponto de vista sonoro-visual os versos se organizam em três conjuntos. Não há correspondência entre o aspecto sintático, por um lado, e sonoro-visual, por outro: a primeira idéia se realiza nos três versos iniciais, cujas rimas são Aab; à segunda idéia correspondem os três últimos versos, cujo esquema é BCC. Desse modo, a coesão sintática interrompe a continuidade sonora e visual, havendo um corte de sentido que entra em desacordo com a rima dos dois versos centrais do poema. Há, pois, um descompasso entre os aspectos visual e sonoro, por um lado, e o aspecto sintático, por outro. Não obstante, apesar da desarmonia entre sonoridade e sentido, os versos terceiro e quarto, que pertencem a unidades diferentes, por sua rima funcionam como elo entre as duas unidades de sentido que compõem o poema.

Nesse madrigal, ao modo de um diálogo, o poeta - "eu" - se dirige a Anarda - "tu". Primeira e segunda pessoas aparecem em significativo desequilíbrio: o amante faz-se presente na maioria dos versos do poema, pelos possessivos e desinências verbais próprias da primeira pessoa - como em "veo", "mi deseo", "mi corazón" e "la amorosa llama" (nessa última expressão, como vimos, a marca de primeira pessoa está subentendida). O destinatário aparece em dois momentos: em simultaneidade com o emissor, no verso que inaugura o poema, "Cuando las luces de tus ojos veo"; e no penúltimo verso, "Las que en tus ojos son luces vivientes". Em ambas as ocorrências, a segunda pessoa se expressa pela presença do pronome possessivo a ela correspondente, o qual determina sempre a mesma palavra "olhos": "tus ojos". Se o poeta se introduz no poema ao mencionar o ato de ver, o desejo e o coração, que lhe pertencem, a presença de Anarda se faz somente pelos olhos. Duas vezes menciona o poeta o seu coração, e duas vezes os olhos dela: por metonímia, o poeta é o coração; por metonímia, Anarda são os olhos.

Curiosamente, as duas pessoas do diálogo se relacionam de maneira quase que absolutamente excludente. Exceto no primeiro verso do poema, em que ambas aparecem simultaneamente - é nele que Anarda é vista pelo poeta -, nos demais o eu e o tu se alternam, predominando as referências à primeira pessoa. Desse modo - e isso se aplica a cinco dos seis versos do poema - se um verso determinado alude à primeira pessoa, não mencionará a segunda; se se refere à segunda, nele não se apresentará a primeira. A proximidade do poeta 
com sua amada se dá pela visão que tem dos olhos dela, e pelo sentimento que essa visão nele desperta.

\section{Esquema dialogal}

\begin{tabular}{|l|l|}
\hline Primeiro verso: tu - eu & Quarto verso: eu \\
Segundo verso: eu & Quinto verso:tu \\
Terceiro verso: $\quad$ eu & Sexto verso: eu \\
\hline
\end{tabular}

O sentimento do poeta é, portanto, platônico - como se viu, a amada e o poeta não se relacionam, a não ser com a distância resguardada pelo olhar. De tudo isso resulta a inviabilidade da realização concreta do amor, já que o encontro do amante com a sua amada somente se dá pela visão que dela ele tem, como se lê no verso inicial da composição. Embora breve, o contato do amante com a sua amada nele deixa suas marcas. Conforme anuncia o título do poema - "Anarda vista, e amada" -, a Anarda basta vê-la para amá-la.

O madrigal possui uma interessante unidade lexical: grande parte das palavras que nele comparecem pertencem ao campo semântico do fogo. À categoria dos nomes pertencem os substantivos "luces", "llama" e seu plural "llamas", e o adjetivo "ardientes"; entre os verbos foram escolhidos "enciende" e "inflama". Como veremos, esse emprego de palavras relacionadas ao fogo é uma decorrência do conhecimento que o poeta tinha da teoria da visão, não somente pela ciência da época, mas pela tradição greco-latina, de que também era herdeiro.

Desde os tempos mais remotos os olhos foram objeto da reflexão dos filósofos. Acerca desses órgãos do corpo humano e do sentido da visão, coexistiram, na Antigüidade, a "teoria perceptiva" ou "do olhar receptivo", e a "teoria emissiva" ou "do olhar ativo", cujas premissas se opunham mutuamente. Pensadores houve, como Epicuro, que defendiam a idéia de que a visão seria uma atividade passiva: para eles, os olhos, constituídos por átomos de água, seriam os espelhos que refletiriam os átomos de fogo desprendidos pelos objetos, tanto os luminosos como os iluminados.

Outros pensadores, como Platão e seus seguidores, consideravam os olhos como faróis emissores de raios que, por sua luminosidade própria ou por razões de identidade com os corpos igualmente providos de luz, tornariam visíveis os objetos ao se chocarem com eles. Essas formas de pensamento cindiram 
aquilo que, na verdade, é uma unidade: o caráter simultaneamente passivo e ativo do sentido da visão - que, ao mesmo tempo em que depende da existência prévia dos objetos da realidade externa, depende dos olhos de quem vê. ${ }^{9}$

Segundo Alfredo Bosi, a primeira dessas teorias, a do "olhar receptivo", estaria revestida de passividade ao ser "uma vertente materialista, ou, mais rigorosamente, sensualista do ver como receber"; a segunda, a do "olhar ativo", corresponderia a "uma vertente idealista ou mentalista do ver como buscar, captar, , estando, assim, por oposição à primeira, associada à idéia de atividade. Como se vê, segundo esse estudioso, a idéia de passividade está associada ao caráter puramente receptivo do olhar, enquanto a idéia de atividade corresponde, meramente, à capacidade seletiva dos olhos na captação das imagens a serem vistas.

O que une ambas as teorias, resguardadas as diferenças que há entre elas, é o papel que o fogo desempenha no exercício da visão. O fogo estaria ou nos objetos, segundo a teoria perceptiva, ou nos objetos e nos olhos, segundo a teoria emissiva. ${ }^{11}$ A presença de imagens relacionadas ao fogo no madrigal de Botelho de Oliveira, embora não seja suficiente para afirmar que o poeta fosse defensor de uma das duas teorias assinaladas, permite supor que o poeta era conhecedor do pensamento vigente em sua época.

A esse respeito é conveniente que façamos algumas considerações. A aceitação, pela literatura e pela cultura do século XVII, de um conhecimento oriundo da Antigüidade, não se limita a esse caso específico. Em um dos sonetos do Coro das Rimas Castelhanas, intitulado "Encarecimento da fermosura de Anarda", nota-se que, embora houvesse já a ciência progredido no que diz respeito à idéia que se tinha do funcionamento do universo, a literatura da época de Manuel Botelho de Oliveira conservava a teoria postulada, na Antigüidade, por Ptolomeu. Para lograr o encarecimento da formosura de Anarda, entre outras imagens belas tomadas da natureza, no segundo verso do segundo quarteto o poeta faz referência à beleza do sol, que "en la cuarta esfera gira".

9. Sobre essas teorias da visão, cf. CHAUí, 1993, p. 31-63; BOSI, 1993, p. 65-87.

10. BOSI, 1993, p. 65-87. (grifo do autor)

11. Na terminologia empregada por Alfredo Bosi, como ficou dito, à teoria perceptiva e a à teoria emissiva correspondem, respectivamente, a teoria do olhar receptivo e a teoria do olhar ativo. 
Como tivemos ocasião de demonstrar em estudo realizado sobre aquele soneto do poeta baiano, ${ }^{12}$ esse verso encerra uma alusão ao sistema geocêntrico ptolomaico, segundo o qual o cosmo seria um conjunto de oito esferas em cujo centro estaria posicionada a Terra. Gravitando em torno dela estariam os demais corpos celestes, cada um deles ocupando uma das esferas. Segundo a visão do astrônomo grego Ptolomeu ( 100 d.C. - 170 d.C. ), o Sol ocuparia a quarta esfera. Na ocasião em que Botelho escreveu e publicou os seus poemas, o sistema geocêntrico convivia, também entre os cientistas da época, com o sistema heliocêntrico de Copérnico (1473-1543), segundo o qual os planetas realizavam um duplo movimento, em torno de si mesmos e em torno do Sol, centro do universo: sabe-se que, em Salamanca, o estudo do novo sistema passou a ser opcional a partir de 1561. Feitas essas considerações, é conveniente que retomemos a idéia das teorias da visão. Se, para os antigos filósofos, o sentido da visão estava sempre relacionado com o fogo, a diferença entre aquelas duas teorias - a do "olhar receptivo" e a do "olhar ativo" - reside, como ficou dito, no caráter passivo ou ativo atribuído aos olhos. Isto posto, pode-se afirmar que ambas as teorias estão em jogo no madrigal, seja nos olhos do amante, seja nos da amada. É o que trataremos de demonstrar.

A teoria perceptiva da visão está presente no madrigal "Anarda vista, e amada" - assim será, ao menos, se adotarmos o ponto de vista do poeta, cujo sentimento, sob o domínio da visão que ele tem da mulher amada, depende somente dessa imagem. Os olhos do poeta recebem, de maneira involuntária ou passiva, a imagem de Anarda - que neles se reflete como num espelho. A visão, por depender do objeto visto e não dos olhos de quem o vê, é um sentido privado de autonomia. O amor que o poeta sente não é uma decorrência do seu estado volitivo, mas tão-somente da bela imagem gravada em seus olhos. Em outras palavras, ou como disse o poeta, a Anarda basta vêla para amá-la.

Também comparece no madrigal uma idéia derivada da teoria emissiva da visão, para cuja constatação devemos deixar de lado por um momento a perspectiva dos receptivos olhos do poeta e voltar nossa atenção para a descrição feita dos olhos de Anarda: por terem brilho próprio, eles são como faróis que, ao emitirem seus raios, por efeito de um choque deles com o objeto involuntariamente visto, acabam por penetrá-lo.

12. Cf. MIRANDA, 2003-2004, p. 275-276. 
Os olhos de Anarda produzem e emitem faíscas que o poeta recebe, incendiando-se interiormente. O sentimento amoroso nasce, no poeta, pela recepção da luz vinda de Anarda. Se os olhos dele são o espelho que reflete a imagem dela, os olhos dela, por possuírem luz própria, são faróis. Essas duas propriedades associadas ao sentido da visão pelos pensadores da Antigüidade - as propriedades de refletir e de emitir luz - são necessárias à constituição do sentido do poema. Nele está presente, também, a idéia oposta: o poeta vê sua amada porque as emissões de sua visão colidem com ela. Sobre o processo de disseminação de imagens através do ar, escreveu Leonardo da Vinci: "El aire está lleno de infinidad de imágenes de objetos desparramados en él. Todos estos objetos están representados en todos y todos en cada uno de ellos."

Os olhos do poeta são o canal por meio do qual os olhos da amada fazem-lhe acender no coração o sentimento do amor. Essa é uma decorrência de ser o olho o órgão do corpo humano que permite ao homem entrar em contato com a realidade que lhe é exterior. Essa idéia pertence à ciência da época. Algum tempo antes, Leonardo da Vinci afirmava que "el ojo es la ventana del cuerpo bumano a través del cual [el alma] descubre su camino y disfruta la belleza del mundo". Diz ele ainda: "Gracias ao ojo, el alma permanece contenta en la prisión corporal, porque sin él una prisión asi sería una tortura."

O olho recebe o que lhe vem de fora: o conhecimento desse fenômeno permitiu que Leonardo da Vinci empregasse, em seu texto, a analogia entre olho e janela, idéia ainda hoje corrente. Como se viu, é por meio do sentido da visão que o indivíduo tem notícia da realidade que o cerca, e as informações que desse modo recebe podem operar mudanças em sua realidade interior.

Botelho de Oliveira sabia que o olho permite um duplo relacionamento entre o ser humano e a realidade. A janela do olho permite ver o exterior e, de igual modo, pode denunciar o que vai no interior. O olho é, assim, para o poeta, um "meio de comunicação" perfeito, já que transmite ao exterior o que vai na interioridade e, ao mesmo tempo, lhe dá ciência do mundo.

Se no madrigal "Anarda vista, e amada" a idéia da visão que ali está manifesta é aquela que concebe o olho como porta de entrada para a

13. DA VINCI, 1995, p. 13.

14. DA VINCI, 1995, p. 11. 
informação vinda de fora, num outro madrigal, "Amor declarado pelos olhos", ao olho é dado funcionar como porta de saída para o que lhe vai na alma. Já ficou demonstrado que o olho é janela para entrar. Fica por demonstrar que o olho é janela também para sair. É o que faremos a seguir.

\section{III}

\section{AMOR DECLARADO PELOS OLHOS}

madrigal VI

Cuando inflama escondido

El fuego en sus ardores repetido,

Sube la llama, y luego

Por los balcones se publica el fuego;

Si mi fuego me inflama,

Sube a los ojos la amorosa llama,

Y si a los ojos, cual balcón, se aplica,

Mi fuego muestra, y mi pasión publica.

Este madrigal, o sexto das rimas castelhanas, está constituído por uma única estrofe de oito versos com rimas emparelhadas. Nas oito unidades métricas de que se compõe, constata-se a alternância de versos hendecassílabos e heptassílabos, organizados conforme o esquema aAbBcCDD. Como se vê, a prevalência dos versos de onze sílabas se impõe pelo par de versos final - de hendecassílabos - já que nos seis primeiros versos do poema, quanto ao metro empregado, há uma equilibrada alternância.

O quarto verso, pela pontuação diferenciada com relação aos que o antecedem - já que é o único a terminar por ponto-e-vírgula -, marca um corte, de modo a dividir o poema em dois blocos de idéias. Os quatro primeiros versos, cujo esquema de rimas é aAbB, contêm uma só idéia; neles, o poeta se refere a algo que, pertencendo ao mundo, pode ser por toda a gente constatado. O que ele diz é: "Quando o fogo que arde escondido alteia sua chama, torna-se visível pelas janelas e varandas". O que faz o poeta é descrever um incêndio que se produz no interior de um edifício. Tal incêndio, havendose iniciado de maneira tímida, não foi visto e por isto pôde se propagar. Somente se torna público quando as chamas chegam às varandas do edifício, por onde pode ser visto. Nessa primeira quadra o poeta busca no mundo 
exterior as imagens que lhe servem de símile para a realidade invisível que deseja expressar.

Nos quatro versos seguintes, cujo esquema de rimas é cCDD, há duas unidades nocionais - a cada uma correspondendo um par de versos. No primeiro deles, o que ele diz é: "Se o meu fogo me inflama, sobe aos olhos a amorosa chama." No outro, de estrutura mais complexa, diz: "E se [essa chama amorosa] alcança os olhos, como se eles fossem uma varanda, meu fogo e minha paixão se tornam visíveis ao mundo."

Construído o símile no primeiro bloco de versos do madrigal, no segundo as imagens buscadas no mundo entram em correspondência com a realidade interior do poeta. A comparação entre as varandas do edifício e os olhos do poeta, no entanto, só é feita no último par de versos. A correspondência entre a imagem da primeira parte do poema e a idéia que se manifesta na segunda parte anda de par com a maior extensão dos versos. Assim, os três primeiros pares de versos do poema, compostos cada um por um verso heptassílabo e um hendecassílabo, falam ou da realidade exterior (os dois primeiros) ou da realidade interior (o terceiro). Já o último conjunto de dois versos, que se distingue por ser composto por dois hendecassílabos, reúne os elementos de um campo e de outro: os olhos são para o poeta o que as varandas são para o edifício.

O sentimento que se ateia no coração do amante dá pelos olhos sinais de sua existência. Tal como o fogo, que se torna visível quando chega às varandas do edifício, a chama amorosa, alcançando os olhos daquele que ama, torna visível e conhecida a paixão que sente. Assim, os olhos são também janelas de saída: é por eles que o amor se comunica ao mundo.

O léxico usado pelo poeta pertence ao mesmo campo semântico daquele usado no Madrigal III, havendo em ambos um predomínio de palavras relacionadas ao fogo e ao calor que ele produz. Neste madrigal, muitas das palavras são mencionadas de maneira reiterada. Assim, "inflama" aparece no primeiro e no quinto versos; "fuego", nos versos segundo, quarto, quinto e oitavo; "llama", nos versos terceiro e sexto. Tal repetição contribui para que ao conteúdo relativo ao mundo interior do poeta se ajuste o símile do incêndio. Assim, para realizar a promessa feita no título do madrigal, o poeta parte de um símile para revelar seu amor.

No tempo de Manuel Botelho de Oliveira, a supremacia da visão frente aos demais sentidos humanos era reconhecida. No Sermão da Sexagésima, 
pregado em 1665, o padre Antônio Vieira, a quem o poeta brasileiro rendeu homenagem póstuma em um dos sonetos das rimas portuguesas, ${ }^{15}$ explicou a relativa importância das palavras, se consideradas em comparação com as ações que se praticam, porque "as palavras ouvem-se, as obras vêem-se; as palavras entram pelos ouvidos, as obras entram pelos olhos, e a nossa alma rende-se muito mais pelos olhos que pelos ouvidos."

Resta-nos ainda dizer algo a respeito da associação que sempre se fez - e ainda hoje se faz -, entre o fogo e o amor. No capítulo intitulado "Psicanálise e pré-história. O complexo de Novalis", do livro A Psicanálise do Fogo, Gaston Bachelard investiga os fatos que possivelmente tenham viabilizado ao homem o conhecimento da tecnologia do fogo. Este autor julga que, a esse respeito, a ciência não tinha oferecido ainda uma hipótese consistente. Bachelard se mostra inconformado com a explicação racional e objetiva que tem sido mais aceita: segundo ela, o homem primitivo chegou a produzir fogo a partir da observação de que, nas florestas, os incêndios se produzem pela fricção dos ramos caídos de algumas árvores, e fundamenta a sua inconformidade dizendo que "o fenômeno em seu aspecto natural jamais foi observado" (as palavras foram escritas em itálico pelo autor), e conclui deste modo o seu raciocínio: "nenhuma das práticas baseadas na fricção, utilizadas pelos povos primitivos para produzir o fogo, pode ser sugerida diretamente por um fenômeno natural." Julgando que a psicanálise pudesse oferecer uma explicação, ainda que arriscada - já que uma descoberta feita por um "espírito primitivo" dificilmente poderia ser explicada pelo pensamento racional e objetivo -, Bachelard faz notar que "a fricção é uma experiência fortemente sexualizada" e que isso é uma decorrência de que teriam sido as experiências íntimas as responsáveis por suscitar no homem primitivo a idéia de produzir fogo mediante a fricção. Segundo Bachelard, "o amor é a primeira hipótese científica para a reprodução objetiva do

15. OLIVEIRA, 1953, tomo I, p. 75.

16. VIEIRA, 1972, p. 101.

17. BACHELARD, 1999, p. 35.

18. BACHELARD, 1999, p. 35.

19. BACHELARD, 1999, p. 37. 
fogo." ${ }^{20}$ E justamente nesse capítulo de seu livro, ele arrola alguns exemplos das idéias que a ciência européia dos séculos XVII e XVIII desenvolveu a respeito do fogo - é possível que Manuel Botelho de Oliveira, tendo estudado em Portugal, conhecesse as especulações que se faziam naquele tempo. Segundo a maioria daquelas que o Bachelard chamou "lendas", as hipóteses partiam do pressuposto de que o fogo estava em conexão com as atividades sexuais do ser humano, o que autoriza ao autor afirmar que "o amor não é senão um fogo a transmitir. O fogo não é senão um amor a surpreender." ${ }^{21}$ Segundo ele, então, o homem primitivo chegou a dominar a tecnologia do fogo porque quis estender o "cálido bem-estar do amor físico", em que geralmente está presente a fricção, a outras experiências de sua vida. E assim aquele homem ter-se-ia visto na contingência de friccionar dois pedaços de madeira, por exemplo, e disso teria resultado a produção do fogo. É desse modo que a psicanálise pode explicar, melhor que as outras ciências - essa é a opinião de Bachelard -, de que modo a tecnologia do fogo chegou a ser dominada pelo ser humano. No capítulo seguinte do mesmo livro, intitulado "O fogo sexualizado", Bachelard afirma que "se a conquista do fogo é, primitivamente, uma 'conquista' sexual, não devemos nos surpreender com que o fogo tenha permanecido sexualizado, por tanto tempo e tão vigorosamente." ${ }^{23}$ Pode não ser a explicação melhor para o início do conhecimento dessa tecnologia, mas é perfeitamente adequada se pensarmos na associação que o ser humano sempre fez, poeta ou não, entre o fogo e o amor. O amor pode explicar o fogo, mas o fogo não pode explicar o amor.

Considerando a interioridade do sentimento, Luís de Camões, em célebre soneto, afirmou que "amor é fogo que arde sem se ver." em Manuel Botelho de Oliveira, a experiência amorosa é diferente: para ele, como vimos, pode o amor ser declarado pelos olhos.

20. BACHELARD, 1999, p. 37.

21. BACHELARD, 1999, p. 38.

22. BACHELARD, 1999, p. 43.

23. BACHELARD, 1999, p. 65.

24. CAMÕES, 1946, p. 228. 
Disponivel em: http://www.letras.ufmg.br/poslit

Abstract: This paper anlyses a couple of madrigals written in spanish by the Brazilian poet Manuel Botelho de Oliveira.

Key words: Brazilian Literature, Brazilian Poetry, Baroque Poetry.

\section{Referências Bibliográficas}

ALMEIDA, Carmelina M. Rodrigues. O marinismo de Botelho. Salvador: UFBA, 1975. (Tese apresentada ao Instituto de Letras da Universidade Federal da Bahia para concurso de Professor Assistente do Departamento de Letras Românicas).

BACHELARD, Gaston. A psicanálise do fogo. São Paulo: Martins Fontes, 1999.

BACHELARD, Gaston. Psicanálise e pré-história. O complexo de Novalis. In: BACHELARD, Gaston. A psicanálise do fogo. São Paulo: Martins Fontes, 1999, capítulo 3, p. 33-63.

BACHELARD, Gaston. O fogo sexualizado. In: BACHELARD, Gaston. A psicanálise do fogo. São Paulo: Martins Fontes, 1999, capítulo 4, p. 65-87.

BAEHR, Rudolf. Manual de versificación española. Madrid: Gredos, 1989.

BOSI, Alfredo. Fenomenologia do olhar. In: NOVAES, Adauto (Org). O olhar. São Paulo: Companhia das Letras,1993, p. 65-87.

CAMÕES, Luis de. Obras completas. Vol. I. Redondilhas e sonetos. Prefácio de Hernani Cidade. Lisboa: Livraria Sá Costa, 1946, p. 228.

CHAUÍ, Marilena. Janela da alma, espelho do mundo. In: NOVAES, Adauto (org.). O olhar. São Paulo: Companhia das Letras, 1993, p.31-63.

DA VINCI, Leonardo. La vista y la apariencia de las cosas. In: Cuadernos de notas. Madrid: M.E. Editores,1995, p.9-26.

MIRANDA, Anne Navarro. Um soneto castelhano de Manuel Botelho de Oliveira. O Eixo e a Roda, Belo Horizonte, v. 9/10, p. 265-285, 2003/2004.

MOISÉS, Massaud. Dicionário de termos literários. 19.ed. São Paulo: Cultrix, 2002.

OLIVEIRA, Manuel Botelho de. Música do Parnasso: dividida em quatro coros de rimas portuguesas, castelhanas, italianas e latinas. Rio de Janeiro: Instituto Nacional do Livro, 1953. t. I.

RIBEIRO, João Roberto Inácio. Música do Parnasso e a poesia latina de Manuel Botelho de Oliveira. Assis, São Paulo: Faculdade de Ciências e Letras da UEP, 1990. (Dissertação de Mestrado.)

RODRIGUES-MOURA, Enrique. Manuel Botelho de Oliveira (1636-1711): un poeta, dos continentes, cuatro idiomas. Texto lido no $50^{\circ}$ Congresso Internacional de Americanistas, em julho de 2000, Varsóvia.

TEIXEIRA, Ivan. O engenhoso fidalgo Manuel Botelho de Oliveira. Revista USP, São Paulo, n. 50, p.178-209, jun./ago. 2001.

VIANNA, Marlene Machado Zica. Música do Parnasso: temas, formas, linguagem. 2001. 2 v. Belo Horizonte: Faculdade de Letras da UFMG. (Tese de Doutorado em Literatura Comparada.)

VIEIRA, Padre Antônio. Sermão da Sexagésima. In: Sermões. Rio de Janeiro: Agir, 1972. p.86-126. 